\title{
Applying Bayesian modelling to assess climate change effects on biofuel production
}

\author{
Camaren Peter $^{1, *}$, Willem de Lange ${ }^{2}$, Josephine K. Musango ${ }^{2}$, Kurt April ${ }^{3}$, \\ Anet Potgieter ${ }^{1}$ \\ ${ }^{1}$ Ndibano: Intelligence in Systems, 245 Private Bag X18, Rondebosch 7701, Cape Town, South Africa \\ ${ }^{2}$ CSIR Natural Resources and the Environment, PO Box 320, Stellenbosch 7599, South Africa \\ ${ }^{3}$ Graduate School of Business, University of Cape Town, Private Bag X3, Rondebosch 7701, Cape Town, South Africa
}

\begin{abstract}
Socioeconomic and ecological systems exhibit complex, interdependent behaviour which is often difficult to model and understand. This is due to the complex reorganisation of key sub-system processes involving nonlinear, cross-scale and cross-sector interactions in real time. Hence, predictive models of complex social-ecological systems are often subject to large uncertainties. We propose an approach for evaluating land-use adaptations for biofuel production, using Bayesian networks and integrating research on the food, water and energy sectors. The approach is intended to facilitate interdisciplinary consideration of cross-scale and intersector dependencies. We applied this approach to 2 examples of land-use strategies and show how the resilience of a strategy that meets the new South African national biofuel production target can be assessed in relation to climate change. Cross-disciplinary consideration of variables may be enhanced through the sensitivity analysis enabled by Bayesian networks, which is used to conceptualise the conditional causal dependencies between subsystem variables. We formulate and run a national scale South African model which links the impacts of projected climate change effects in southern Africa to irrigated agriculture, water storage planning and biofuel production. We demonstrate how the approach can be used to evaluate land-use changes in different projected climate change scenarios and land-use combinations, and how conflicting demands between water, food and biofuel energy sources may be preliminarily identified and assessed in an integrated probabilistic framework. Evaluating this problem in the context of climate change and water-related limits to growth enables research to support integrated analysis and planning for biofuel production and development.
\end{abstract}

KEY WORDS: Bayesian networks · Climate change · Biofuels · Land-use change · Resilience • Cross-sector analysis

Resale or republication not permitted without written consent of the publisher

\section{INTRODUCTION}

Socio-economic development strategies have historically focussed narrowly on local development concerns and have not emphasized cross-sector interactions and dependencies, especially over large spatial and temporal scales (Gunderson \& Holling 2002, Starzomski et al. 2004, Levin 2006). The consideration of long-term and remote effects of ecological exploitation for human development purposes has not historically been a major consideration (Lubchenco 1998). The implications for social-ecological systems are that optimising human development activities at a local scale for short-term, microeconomic gain does not necessarily translate into benefits at the whole-system scale. In particular the effects of local development optimisation efforts have often had significant remote effects in other sectors of the social-ecological system or in components of the ecosystem. These sectors are traditionally viewed as distinct parts of a system and only local dependencies and interactions with other sectors are considered in strategic planning and implementation. 
Biofuel is currently being considered as a supplementary source of low emission, renewable energy as a liquid fuel supplement in agriculture-based economies such as South Africa (DME 2006), and in transitional and industrially developed countries (e.g. Brazil, USA). With the increased global awareness of climate change effects, the pressure to lower emissions has grown. However, the impact of the agricultural sector entering an energy market with rising demands and the threat of lower fossil fuel reserves in the future poses complex intersectoral development challenges. This is perceived to be due to the interdependency that is being created between the energy and food production sectors by the introduction and use of biofuel as a source of alternative energy (MIT 2007, Sugrue \& Douthwaite 2007).

Both climate change effects and regional human development activities (especially significant land-use changes) may threaten water supply and agricultural food production in southern Africa (Mendelsohn et al. 2000, Mukheibir \& Sparks 2003, Midgeley et al. 2005, Kates \& Dasgupta 2007). In the southern African region, climate-change models (Mendelsohn et al. 2000) predict an increase in water scarcity due to temperature increases. For agricultural production this suggests an increase in plant evapotranspiration rates, surface runoff and dam evaporation rates. At the national scale this implies that sector-driven competition between fuel and food producers will increase. Avoiding unintended effects of diverting existing agriculture for food and animal feed to biofuel production requires prescribing an appropriate balance between the agricultural activities of food and biofuel production.

The South African total national biofuel target (Lemmer 2006) for 2013 was originally drafted at $4.5 \%$ of liquid road transport fuels (DME 2007); that is, approximately $8 \%$ of ethanol in national petroleum production $\left(\mathrm{NPP}=10.985 \times 10^{9} \mathrm{l}\right)$ and $2 \%$ biodesel in diesel, which is approximately $4.5 \%$ of national petrol and diesel volumes (DME 2007). Achieving this target across a range of scenarios requires blending in up to 5 and $10 \%$ biofuel components for biodiesel and fuel ethanol, respectively (DME 2006). This target was later slashed to $2 \%$ (i.e. around 400 million $1 \mathrm{yr}^{-1}$; DME 2007) citing concerns over food security in 2007, and the cultivation of maize for ethanol production has been suspended in the initial phase of the strategy. Biofuel production from soya beans, sunflowers and sugarcane on this scale from irrigated agriculture alone may require a large amount of new arable land, and the conversion (to fuelproducing agriculture) of significant areas of land on which food-producing agriculture (especially subsistence agriculture) is currently being practised.

Between academic disciplines, economic sectors, civil society and governance bodies, there is a debate on the national biofuel development strategy. Climate-change adaptation strategies involving land-use changes that aim to develop the biofuel sector holistically and sustainably require that the effects of climate change on production limits and intersectoral dependencies are taken into account. This study outlines an approach to assess what scenarios may create the conditions for conflicting sectoral interests to play out in response to the biofuel strategy being proposed.

The aim of this study is to show how interdisciplinary multi-participant cooperation around intersectoral effects can be enhanced by using a Bayesian model to assess land-use adaptation strategies against multiple future scenarios - i.e. to establish an understanding of a multi-sector, social-ecological system in an analytical framework which could help support a multiparticipatory approach. The focus of our analysis is on testing the land-use combinations that can help attain biofuel production targets; and in particular, exploring the sensitivity of surpluses that would be required to meet targets under climate change effects. To this end, we apply the approach to 2 examples of hypothetical land-use combinations, and test these strategies against projected climate change effects for the region regarding rainfall and temperature variation. This study is therefore an illustrative and descriptive study, and is not an exhaustive study of the multitude of future options, nor is it definitive in terms of prediction.

The approach proposed in this study provides a framework in which subtle changes-resulting from the exposure of different land-use combinations to projected climate change scenarios-may be evaluated against each other. We argue (and show) that this Bayesian framework constitutes an adaptive, flexible framework that can test a wide range of system configurations against envisaged future system scenarios; especially where land-use changes (or adaptations) are concerned. In particular, the food, water and energy sectors are considered in an integrated framework in which biofuel development strategies being considered in South Africa may be evaluated against its cross-sector impacts on other critical sectors, in particular; regarding food security. The framework is formulated using graphical causal maps and Bayesian networks in interdisciplinary workshops where interdisciplinary and multi-sector concerns of the system may be formulated and tested.

\section{METHODOLOGY}

\subsection{Background}

Studies of the suitability of Bayesian nets for modelling the challenges facing social-ecological systems have recently emerged. Bayesian nets have been used 
to model environmental decision support (Baran \& Jantunen 2004), biophysical systems (e.g. integrating estuarine eutrophication models; Borsuk et al. 2004) and integrated water resource planning (Bromley et al. 2005). In the approach used in this study, large- and small-scale spatio-temporal system interdependencies may be considered within an integrated framework. This framework can be used to consider (1) biofuel production options in relation to land-use strategies, and (2) crop production sensitivities to climate change effects. The approach helped us to formulate a Bayesian model which provides a probabilistic framework of driver-response mechanisms acting across scales and sectors.

We used a case study formulated in previous research (Musango \& Peter 2007) to assess the feasibility of the current, revised biofuel production targets (DME 2007). We adapted the model in Musango \& Peter (2007) to assess the impact of climate change on irrigated agriculture in South Africa using Bayesian networks. We formulated and ran a national-scale South African model which links the impacts of predicted climate-change effects (e.g. changes in temperature and rainfall) to irrigated agricultural activities, water-storage planning and biofuel production. Using the model we explored ways of assessing the resilience of 2 possible biofuel-related land-use strategies (or land-use adaptations) to various climate-change scenarios.

We evaluated adaptation responses in a Bayesian modelling framework and assessed the relative tradeoffs of increased biofuel production in terms of food crop production and impacts on water supply. Through the sensitivity analysis provided by Bayesian nets, the study provided an enhanced understanding of crossscale and cross-sector (e.g. food and energy) activities, with particular respect to the critical limits and thresholds to the growth of crops as biofuel feedstock in relation to climate change. This could form the basis for facilitation of interdisciplinary cooperation. The approach provided a probabilistic framework for sensitivity analysis of cross-scale and cross-sector interdependencies in a variety of scenarios and land-use combinations. The Bayesian framework can merge quantitative data sources and qualitatively (or subjectively) assessed variables with varying levels of confidence (Demirez et al. 2006) in the conditional causal belief structure of the Bayesian Network. System interdependencies and sensitivities may be manually changed within this framework to reflect unfolding contextual changes and improved understanding of system features. Expert opinion and information obtained from the literature and other data was used to constrain the probabilities in the Bayesian model.

The scenarios were formulated with an understanding of regional climate change projections for the
African continent and southern Africa in particular (Mendelsohn et al. 2000, Midgeley et al. 2005), and from the results of global climate change modelling (Bates et al. 2008). These regional climate change models project a general increase in temperatures over the southern African region. More detailed projections indicate that rainfall may decrease in the west (Midgeley et al. 2005) and increase in the eastern part of the country. The model that was formulated and tested in this study does not provide a spatial account of activities in South Africa. Instead, activities are aggregated at the national scale, i.e. each activity is assessed independently of its local spatial context. The system is evaluated at a cumulative scale, and the modelling challenge lies in assessing the scale and level of description required for modelling critical interdependencies that govern the behaviour of the system. The flexibility provided by the Bayesian modelling framework enables different scenarios and adaptation responses to be appropriately formulated and tested at this scale.

We show how key sensitivities between subsystem components and with the external system environment may be elucidated and assessed (and verified) and how sensitivities change depending on the scenario under which the social-ecological system is being assessed. The approach integrates top-down and bottom-up learning in a traceable process (Peter 2008), and may be used to enable interdisciplinary consideration and scrutiny of land-use strategies under a variety of proposed scenarios. This may also be used to stimulate dialogue and debate between various decision makers and help create a shared understanding of cross-sector and cross-scale dependencies which have a significant impact at the system scale (Peter 2008).

The critical difference between Bayesian models and dynamic simulation models such as STELLA and VENSIM is that Bayesian models are probabilitytheory based models i.e. probability distributions are used to model interactions between processes, variables, events, stocks, flows, etc. Moreover, variables are related through conditional causality, i.e. a reason must exist for the causal relationship between any parent and child variable (node). Maximum-likelihood based (versus probability-based) statistical approaches rely on correlations as evidence for relationships, without necessarily explaining causality. This leads to the often lamented ignominy of 'spurious correlations', which often brings statistical evidence into question. Scientific hypotheses are based on articulating the conditional dependences upon which causal relationships are assumed to exist, and to make predictions from that understanding. Bayesian networks and graphical causal models force researchers to articulate the assumptions that underlie the conditional causal 
relationships that they believe exist between variables in a Bayesian network. They therefore provide a rigorous interrogation framework for investigation of scientific research hypotheses.

A hierarchy of land-use model human decision-making complexity was proposed by Agarwal et al. (2000, their Table 2.2). In this hierarchy, probability-based models - such as the one used in our study-rank at the 4 th level of complexity, below single-agent landuse models (Level 5) and multi-agent land-use models (Level 6). The larger volume of variables included in the model provides the flexibility to test a variety of scenarios and adaptations. Decision-makers are constantly faced with 'whitewaters' (Malhotra 1999), where emergent or unforeseeable changes occur, which change the context or nature of the problem to such a degree that flexible, modular modelling frameworks are required to easily reconfigure subsystem modules. With Bayesian networks this is a 'cut-and-paste' task, as editing the model is enabled with Bayesian software. Bayesian networks were chosen for this task because of the wide range of scenarios, and a wide range of adaptation options could be catered for within the framework, which provides adaptability and modularity. Moreover, Bayesian networks make evident the difference between observational and interventional variables (Meder et al. 2009), allowing researchers and decision-makers to have a clear understanding of where to measure and monitor within a system, and where to make interventions (respectively).

\subsection{Conceptualising and formulating the model}

Interdisciplinary cooperation was employed for model formulation and verification. A graphical causal model of the various sub-models formulated in an integrated Bayesian framework is shown in Fig. 1. The model is formulated to evaluate the economic value added (VAD) of water to agricultural production and water use in relation to water storage and climate driven changes in annual temperature and rainfall, and, comparing this with results obtained from scenarios that are run without considering climate driven changes and water losses from water storage in dams. The model has 4 basic modules which are outlined in Fig. 1 and shown in detail in Fig. 2. The economics modules calculate the economic VAD to water (and water use) through food-based agriculture with and without climate change effects (Fig. 2a,b). The biofuel production module (Fig. 2c) enables the user to increase the area of a crop under production, and dedicate a percentage of the yield to biofuel production and calculates the resulting biodiesel and bioethanol production. The water storage, temperature and rain-

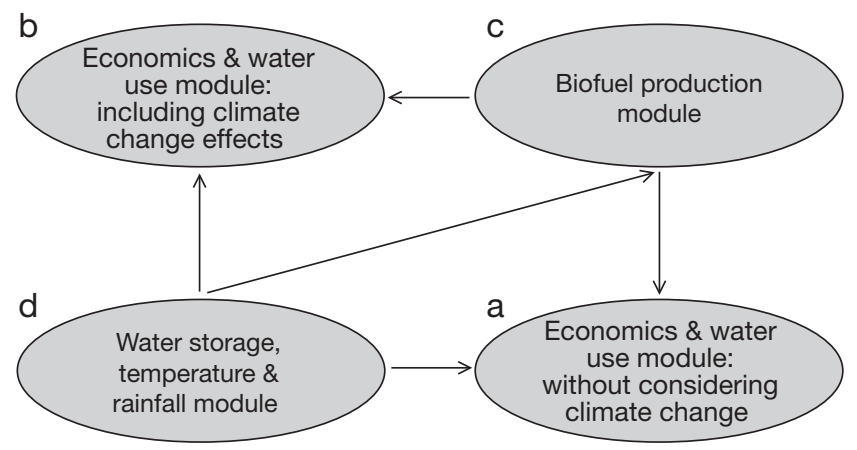

Fig. 1. Sub-models of Bayesian agro-water-biofuels model for South Africa

fall module (Fig. 2d) enables the user to assess the impact of climatic changes in rainfall and precipitation on the total amount of water available. The 4 th module (Fig. 2a) calculates what the envisaged water use would be for planners who did not consider climate change effects.

The conceptual framework of total economic value (TEV) (Blignaut \& de Wit 2004) goes beyond the utilitybased approach of neoclassical economics by considering a wide range of ecological services provided by ecosystems, ranging from ecosystems as sources or sinks to ecosystems as providers of human development services (e.g. recreation, spiritual and cultural value). We use the conceptual framework of TEV to define and formulate the linkages between the various sectoral socio-economic and biophysical domains of concern in this study. However, we kept the systems development process as open as possible, and drew on other concepts and frameworks. For example, in a recent study of agricultural services in the Crocodile Basin of the Incomati catchment, Hassan (2003) used direct and total VAD to assess the value of sugar cane, subtropical fruit and forestry activities. We use the economic multipliers derived in this study to evaluate both direct and total VAD derived from water use in human activities as proxies to help compare the micro- and macroeconomic impacts of adaptation strategies, within the broader TEV framework.

Emission reductions due to the inclusion of biofuel in petroleum may be deduced using estimated conversion rates for emission reductions from the percentage of biofuel added to the national petroleum supply. For example, the carbon dioxide extracted from wheat amounts to roughly one-third of the wheat ground (Lemmer 2006). Other indicators of interest which are not explicitly calculated in the model may be inferred from the model outputs. There are estimates available for the VAD contributed through agricultural production of biofuel feedstock. For example, $1 \mathrm{t}$ of ground wheat is estimated to yield a VAD of 243 South African rand (Lemmer 2006). 


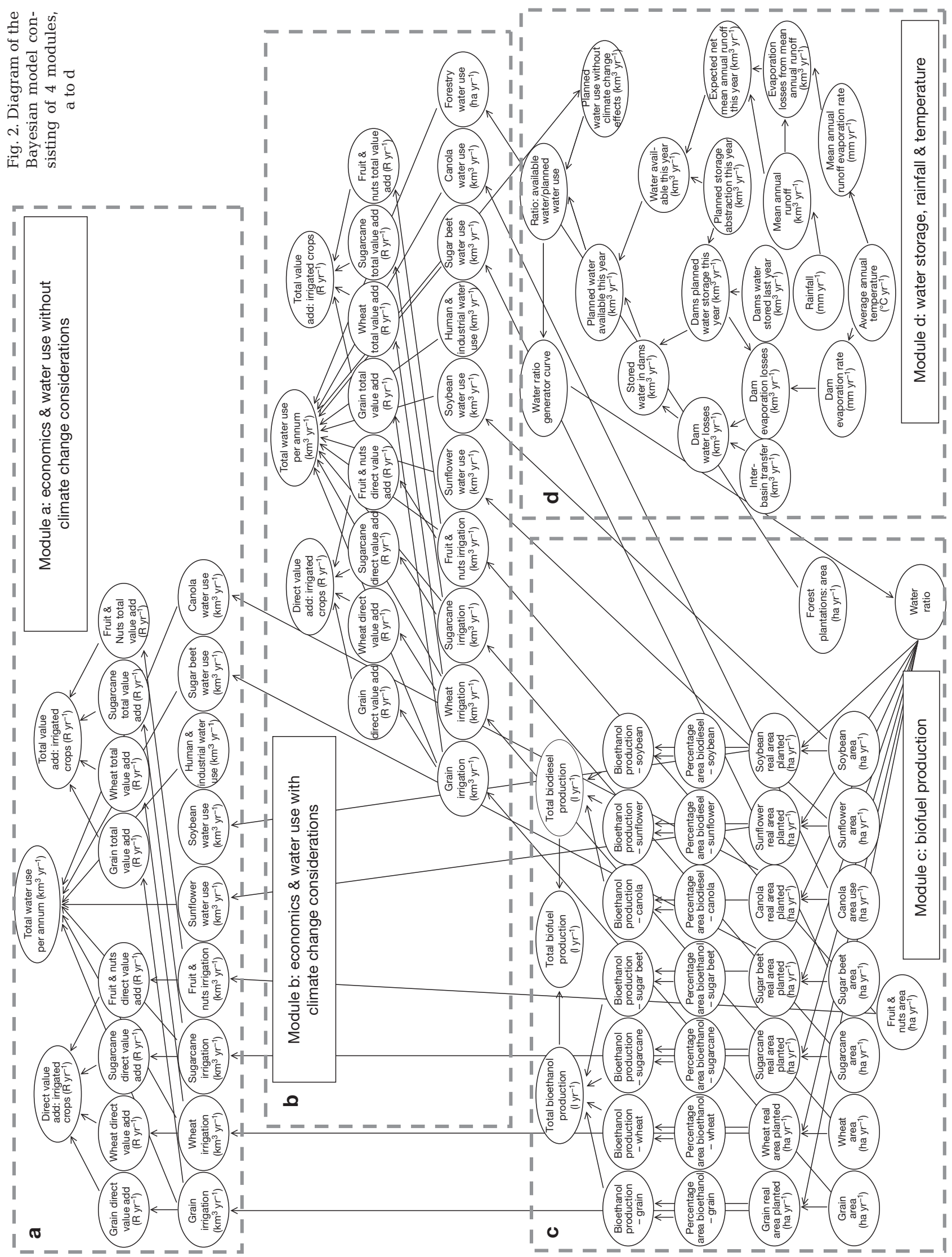




\subsubsection{Populating the model}

The best available information and expert opinion was used to populate and verify the model-which is based on Musango \& Peter (2007). The use of economic multipliers for water-intensive activites derived by Hassan (2003) are used to assess and compare the relative changes in micro- and macroeconomic effects of water adaptation strategies, even though the actual values of multipliers may be contentious. Information regarding the national biofuel strategy (DME 2006) and the bioethanol production feasibility of a plant in the Western Cape (Lemmer 2006) was used to obtain an idea of the national and provincial considerations made in formulating a biofuel development strategy. Dam evaporation rates were obtained from the South African Council for Scientific and Industrial Research (CSIR) records and reports. Information about current levels of irrigated agricultural activities was obtained from several local and international sources (e.g.
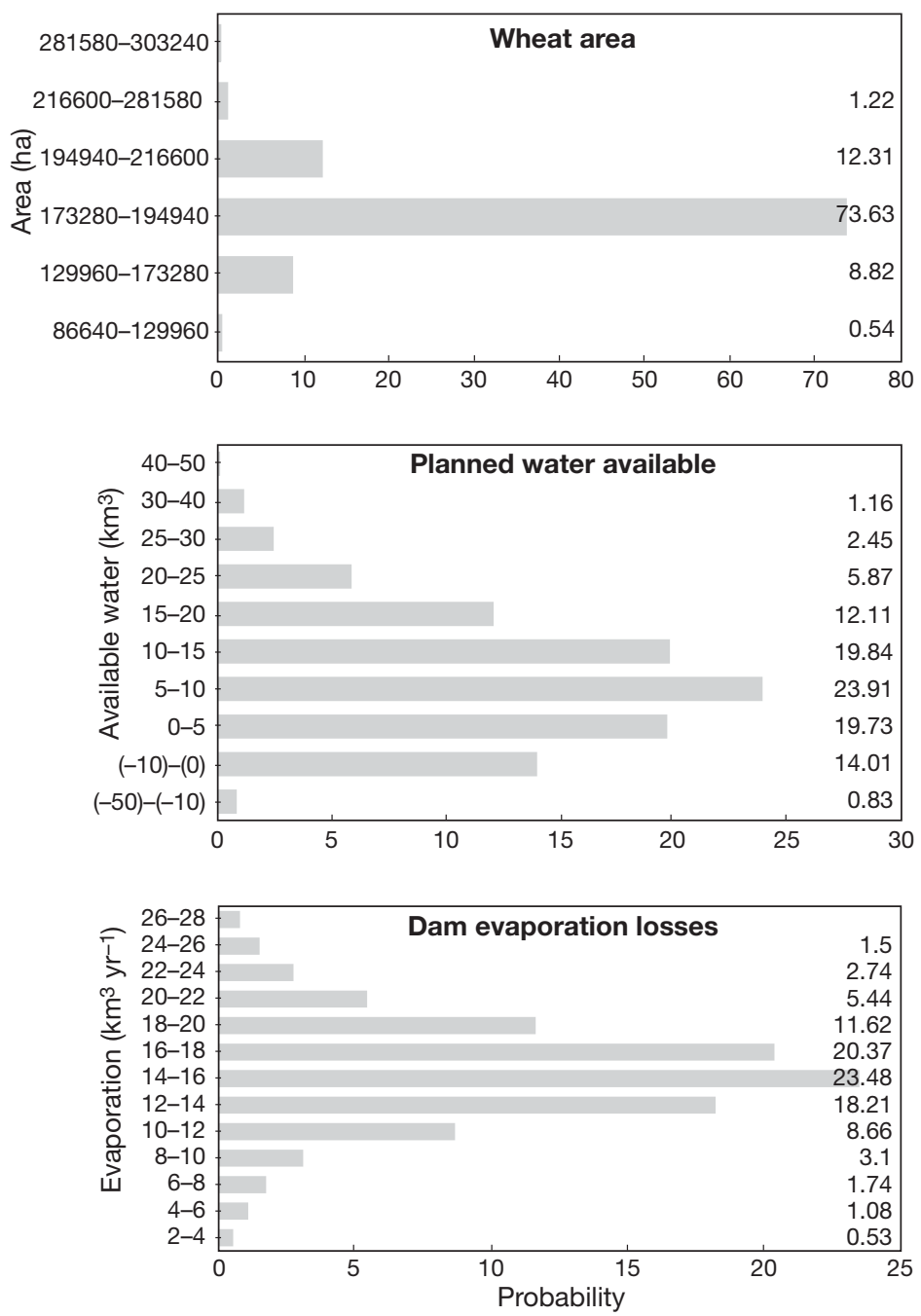

Fig. 3. Initial states of selected variables. The probability of the variable being in any state is shown as a discrete probability distribution over the range of states for each variable
AQUASTAT 2005). All sources were compared and verified before use. Traceability of model parameters and the reasoning behind using them is captured in the graphical causal modelling software that is used to formulate Bayesian nets and may therefore be shared and scrutinised amongst researchers.

Probability distributions from empirical or theoretical frameworks (e.g. through detailed subsystem models) can be used, as can conditional probability tables populated with expert understanding and verified in sensitivity analyses. Critically, the probabilities in the model reflect the 'current state' of the system, as estimated and projected from data sources that may be a few years old (e.g. census data), and may constitute the only available data, forcing the team to make an estimate (based on an understanding of evolving growth patterns) of the current state of the variable (e.g. the marginal distribution for area under a particular crop such as soya). Therefore, standard deviations from historical data about the history of soya cultivation area
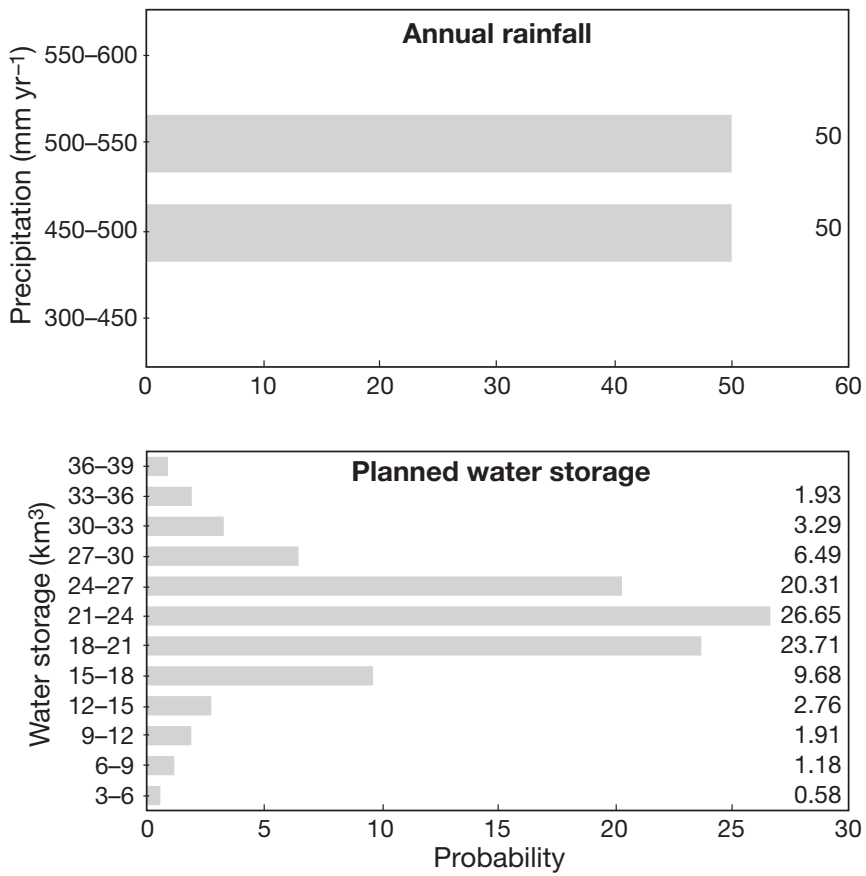
are not used to characterise the probability. Rather, the extent of uncertainty in the estimated 'current state' of area under soya production is reflected, i.e. the uncertainty around the shared knowledge of the interdisciplinary group. In other Bayesian modelling applications - such as to asset management by Demirez et al. (2006) where up-to-date real-time information is available, and the historical patterns of change have some relevance-historical standard deviations can be used. By characterising the variables to reflect the 'current state' (subjectively estimated), the Bayesian model in its default state reverts to a baseline state representing the shared understanding of the expert group of what the 'current state' of the system is, to which all scenarios can be compared.

In general, most of the model makes use of equations with reliable constraints to relate probability distributions between variables. The constraints governing these equations are generally well understood, and while the Bayesian modules deal more explicitly with cumulative effects rather than considering spatial and temporal differences during the period of a year, their outputs are verifiable. There are 2 ways of characterising the probabilities: with (1) discrete and (2) continuous probability distributions. Both ways make use of the Bayesian conditional probability principle to relate variables in causal relationships. In this study, discrete probability distributions were used, as they allow the user to add new evidence to the Bayesian model and update the model to reflect new understanding (Demirez et al. 2006).

Very few variables were subjectively characterised in this Bayesian model (using expert opinion to formulate conditional probability tables, CPTs), and the few variables that were subjective, were verified against expert opinion and understanding of the limits and thresholds of the system under different scenarios (e.g. see the curve in Fig. 4, generated from a conditional probability table). To emphasise, these outputs can be verified against empirical, and modelled evidence, and output, driver and constraint values of the Bayesian network are verified in each scenario. If the marginal and a priori probability distributions are incorrectly determined then the outputs will also be nonsensical. Therefore, input-output relationships are carefully scrutinised and verified by experts for each scenario.

\subsubsection{Sensitivity analysis and running the model}

When running the Bayesian model using a Bayesian software interface, the probability distribution of each selected variable may be viewed. The parameters of states (or intervals) chosen for agricultural land-use driver variables are shown in Table 1, and the initial states for a selection of critical variables are shown in Fig. 3. The probability of the variable being in any state is shown as a discrete probability distribution over the range of states for each variable. Before the model is run, variables are automatically initialised to defaults representing current value settings (e.g. the wheat area variable in Fig. 3 has a $73.64 \%$ chance of being in the interval, or state: 173280 to 194940 ha). Sensitivity analysis is conducted by varying the values of driver variable states (i.e. $100 \%$ in a single state) and observing response variable distributions.

For each scenario, the response variables are verified for the full range of driver variables. Biodiesel, bioethanol and biofuel production at the aggregate and individual levels are verified. This curve in particular shows that a standard relationship has been used to represent the non-linear response of crops to water, i.e. at first they will grow in response to available water, but growth ceases when heavy rainfall or flooding conditions are approached. This limit is set when 8 times the annual rainfall is obtained. Some response variable values are verified using calculations, while others are verified using information available online, such as census data. These, and expert judgement, were used to formulate equations between variables that are conditionally dependent (or causally related) in the Bayesian network. For the curves shown in Fig. 4

Table 1. Specifications of land-use change Strategies 1 and 2 (S1, S2): increased crop area and percentage of crops used for biofuel production

\begin{tabular}{|c|c|c|c|c|c|c|c|}
\hline \multirow[t]{2}{*}{ Crop } & \multicolumn{3}{|c|}{ - Area (ha) } & \multicolumn{2}{|c|}{$\begin{array}{c}\text { Area increase } \\
\text { (ha) }\end{array}$} & \multicolumn{2}{|c|}{$\begin{array}{l}\text { Crop used in } \\
\text { production }(\%)\end{array}$} \\
\hline & Current & $\mathrm{S} 1$ & $\mathrm{~S} 2$ & S1 & $\mathrm{S} 2$ & $\mathrm{~S} 1$ & $\mathrm{~S} 2$ \\
\hline Soy & 0 to 5200 & 57200 to 62400 & 78000 to 83200 & 57200 & 78000 & 85 & 85 \\
\hline Sunflower & 10000 to 20000 & 70000 to 80000 & 80000 to 90000 & 60000 & 60000 & 85 & 85 \\
\hline Canola & 0 to 15000 & 105000 to 120000 & 150000 to 165000 & 105000 & 1500000 & 85 & 85 \\
\hline Sugar beet & 0 to 10000 & 40000 to 50000 & 70000 to 80000 & 40000 & 70000 & 75 & 75 \\
\hline Sugar cane & 72000 to 81000 & 90000 to 99000 & 72000 to 81000 & 18000 & 18000 & 65 & 65 \\
\hline Wheat & 173280 to 194940 & 0 to 43320 & 173280 to 194940 & -162450 & 0 & 5 & 5 \\
\hline Maize & 103040 to 115920 & 0 to 25760 & 103040 to 115920 & -115920 & 0 & 5 & 5 \\
\hline Total & 400190 & 402020 & 776190 & 1830 & 376000 & & \\
\hline
\end{tabular}



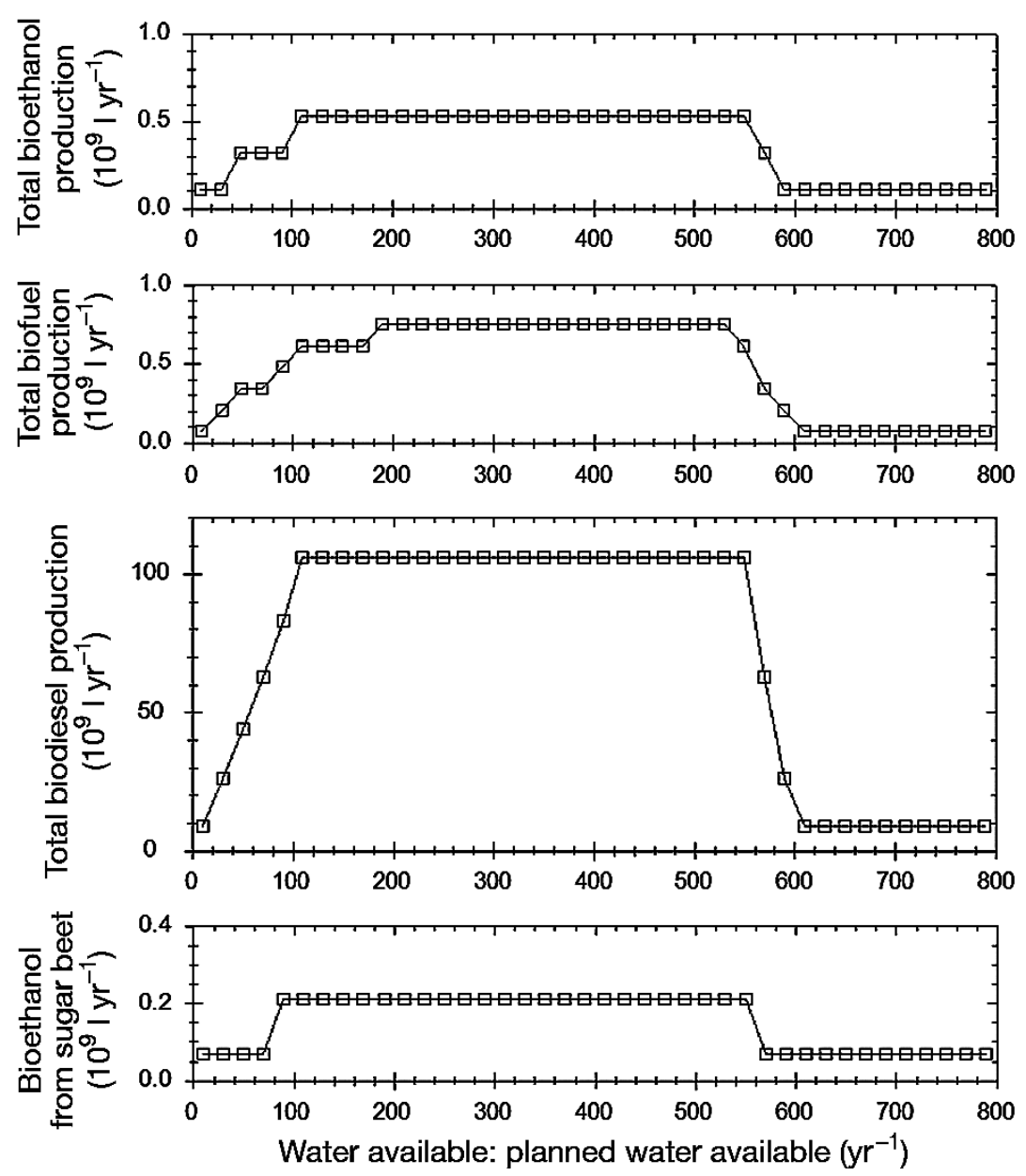

Fig. 4. Sensitivity analysis of biofuel production to the ratio of the actual availability of water over the water that was planned for
Two different land-use growth strategies were identified that meet the South African biofuel production target (i.e. approximately $2 \%$ or $400 \times 10^{6}$ l) of national liquid fuel supply in 2008, i.e. Strategy 1 and Strategy 2. Each strategy's constraint parameters and responses (for no change in annual climate parameters) are shown in Tables 1 and 2 respectively. These particular strategies each represent one possible land-use combination that meets the production target. There are feasibly more land-use combinations that would enable the national biofuel target, but these particular land-use combinations are evaluated and presented in this study, in order to illustrate the value of the modelling approach.

These land-use combinations, or strategies, were chosen to illustrate how each strategy's sensitivity to different climate change scenarios can be assessed using the approach proposed in this study. They take into account the revisions made in the final national biofuel strategy, which discounted maize and jatropha to alleviate concerns over food security, and proposes sugar cane, sugar beet, biodiesel sunflower, canola and soy beans. These crops are intended to be grown in the short term by small-scale farmers in the former rural homelands such as the Eastern Cape, under dryland conditions. However, one of the key aims of the introduction of biofuel

we are interested principally in the growth conditionswhich are mainly linear-resulting in a plateau where adding more water will not result in more yield. There is an approximate 15 to $20 \%$ error associated with assessments made from the probabilities used in this model, which is typical of Bayesian network models, where each variable requires a minimum of 5 states (in $20 \%$ quantiles) to be characterised by a probability distribution.

\subsection{Testing land-use strategies in different climate change scenarios}

A range of land-use combinations was considered with the purpose of converging upon the minimum requirements for enabling the national biofuel target. We incrementally increased the growth of each crop and established what scale of growth would be required to reach the target, and how much of the crops would have to be supplied for biofuel. into the liquid fuel supply is to reduce emissions. In order for the market penetration of biofuel to have a significant impact on emissions savings, larger volumes of biofuel would need to be produced and would necessarily occur at the national scale. Furthermore, biofuel production is easily decentralized and it is foreseeable that as local production centres spread, involved. As the demand for biofuel grows it is likely that irrigated farming of mainly animal feedstock and crops for human consumption might be converted to biofuel feedstock production in different parts of the country, and that irrigated agriculture, which has a limited water supply in South Africa, may come under pressure. The present study explores this pressure, and focuses on the sensitivity of national irrigated agriculture to climate change effects. The sensitivity of areas of dryland crop cultivation to changes in rainfall and precipitation will be much greater as variations in rainfall patterns would have greater effects on the vulnerability of crops that do not have guaranteed water local farmers all over the country will become more 


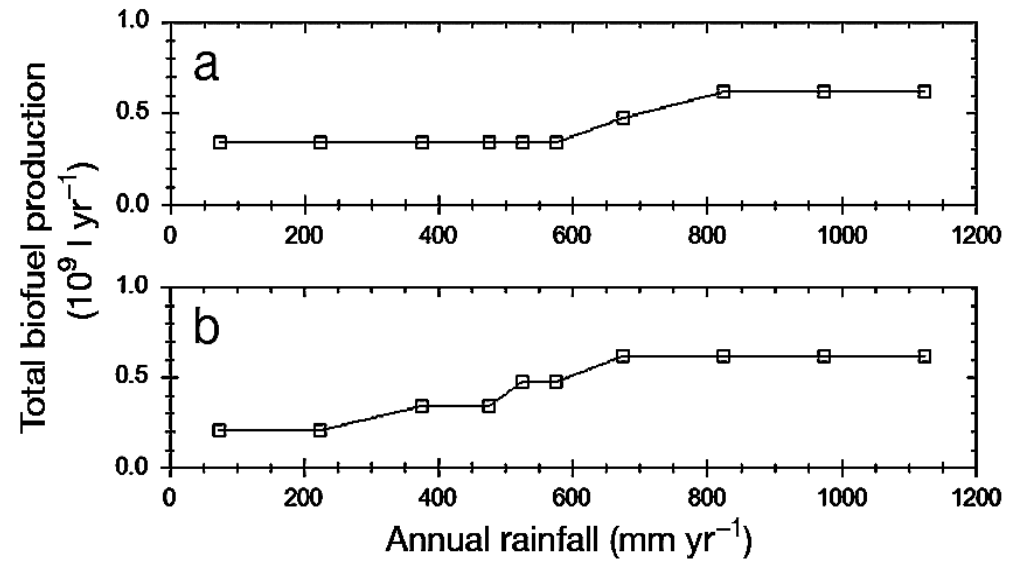

Fig. 5. Comparing (a) Strategy 1 and (b) Strategy 2: increased annual rainfall improves chances of achieving national biofuel production target over the rainfall range to identify how this limits crop production. A temperature range is used, so that the scenarios cater for a range of possible annual temperature variations, as the predictions from global climate change models for 2099 (Bates et al. 2008) cannot simply be linearly regressed in order to determine possible temperature changes in the short and medium terms (Bates et al. 2008). Temperature variations due to climate change are likely to vary significantly from the values obtained through linear regression over a period of $100 \mathrm{yr}$.

The agricultural expansion Strategies 1 and 2 are specified in Tables $1 \& 2$. These percentages were iteratively determined, after testing various growth strategies supply. Therefore, to some extent this study focuses on a best-case scenario for biofuel feedstock production. The details for implementing the national biofuel strategy in the Eastern Cape are still ongoing, and the model built for this study may be further developed in future work to assess the specific dimensions of the Eastern Cape, linking and detailing the different spatial and temporal scales. However, that is beyond the scope of this study, which focuses on showing how the sensitivity of critical limits - thresholds obtained using Bayesian networks - helps researchers and decisionmakers better understand the limitations of the production of biofuel feedstock. Land-use Strategy 1 excludes maize and wheat and Strategy 2 includes maize and wheat, to compare 2 strategies which include and exclude the commercial sector in biofuel production, respectively.

Groups of scenarios were chosen to illustrate the sensitivity to climate change effects. Group 1 and 2 scenarios are applied to Strategies 1 and 2, and tests both strategies under the same climate change conditions for comparison. In Group 1 scenarios (see Section 3.1) it is shown how the national biofuel production target can be achieved more confidently at higher annual rainfall levels (i.e. $>400 \times 10^{6} 1 \mathrm{yr}^{-1}$ : see Fig. 5) if higher average annual rainfall is obtained (i.e. $>400 \mathrm{~mm} \mathrm{yr}^{-1}$ ). In Group 2 scenarios the temperature is increased incrementally and the strategies evaluated against whether they could provide the surpluses required to meet production targets. The relationships between hectareage and tonnage per crop are well understood and reliably determined and verified against South African census data on agricultural production. These strategic options are tested under different scenarios (i.e. Group 1 and 2 scenarios) to illustrate how Bayesian nets may be used to estimate the robustness of the proposed strategy to possible climate change effects (Mendelsohn et al. 2000).

The land-use strategies may be understood by comparing the driver and response variables with their current values, also shown in Tables $1 \& 2$. In Strategy 1 , the driver variables reflect a situation where commercial irrigated crops such as maize and wheat are excluded from biofuel feedstock production, and Strategy 2 reflects a situation where they are included, but very low percentages (i.e. $5 \%$ ) of maize and wheat crop yields are used as biofuel feedstock. The areas under cultivation of maize and wheat were significantly reduced in Strategy 1, so that sufficient irrigation is available to grow the required crops. The yields obtained from cultivating these areas are sensitive to water availability, and are calculated from crop yields that are biased relative to water availability to the whole system. The relationships which characterise yield variations with water availability are taken to be similar for all crop-types and are denoted by a simpli-

Table 2. Comparing responses to South African land-use growth strategies (Strategies 1 and 2 - see Section 2.3): biofuel production, water availability and planned water use

\begin{tabular}{|lccccc|}
\hline & $\begin{array}{c}\text { Planned water } \\
\text { available } \\
\left(\mathrm{km}^{3} \mathrm{yr}^{-1}\right)\end{array}$ & $\begin{array}{c}\text { Total planned } \\
\text { water use } \\
\left(\mathrm{km}^{3} \mathrm{yr}^{-1}\right)\end{array}$ & $\begin{array}{c}\text { Bioethanol } \\
\text { production } \\
\left(10^{6} 1 \mathrm{yr}^{-1}\right)\end{array}$ & $\begin{array}{c}\text { Biodiesel } \\
\text { production } \\
\left(10^{6} \mathrm{yr}^{-1}\right)\end{array}$ & $\begin{array}{c}\text { Biofuel } \\
\text { production } \\
\left(10^{6} \mathrm{yr}^{-1}\right)\end{array}$ \\
\hline Initial & 5 to 10 & 11.59 to 12.98 & $0+$ Residual & 0 + Residual & $0+$ Residual \\
Strategy 1 & 5 to 10 & 10.39 to 11.59 & 211 to 422 & 72 to 94 & 408 to 545 \\
Strategy 2 & 5 to 10 & 11.69 to 12.98 & 211 to 422 & 72 to 94 & $\sim 408$ \\
\hline
\end{tabular}


fied s-shaped growth curve with a non-linear drop-off, i.e. too little or too much water per area farmed results in crop yield losses (see Fig. 4). Lastly, percentages of the total annual projected yield (as modelled) of each crop are used for bioethanol and biodiesel production as shown in Table 1, i.e. the percentage contribution of annual crop production is used as biofuel feedstock. For each hectare of maize, grain, wheat, sugar cane, soybeans and sunflower seeds cultivated, biofuel production of 542, 2016, 1014, 86 and 536 1, respectively, is assumed feasible and is consistent with that in online and published literature and discussions on the subject (Lemmer 2006). In these strategies it is feasible that approximately 400 to $500 \times 10^{6} 1$ of the aforementioned target of around $2 \%$ of national petroleum production (see Table 2) can be obtained, but requiring, under Strategy 1, a significant expansion (280 200 ha) of the crop types chosen in the national strategy, i.e. sugar cane, sugar beet, biodiesel sunflower, canola and soy beans, and a significant reduction in irrigated commercial maize and wheat, leaving an overall moderate expansion of 1830 ha. In Strategy 2, an expansion of 376000 ha in total, including maize and wheat, is required to meet the target.

\section{RESULTS}

In Group 1 scenarios the availability of water in the national system for irrigation was considered. Biofuel production sensitivities to rainfall are illustrated. In Group 2 scenarios, the robustness of the strategy against annual temperature increases was evaluated.

\subsection{Group 1 scenarios: sensitivity to rainfall}

The annual average rainfall was increased (in the Bayesian model) across the range 0 to $1200 \mathrm{~mm} \mathrm{yr}^{-1}$ for both Strategies 1 and 2. The strategies being evaluated were shown to be more feasible in high rainfall years (Fig. 5); exceeding $\sim 600 \mathrm{~mm} \mathrm{yr}^{-1}$ in Strategy 1 and exceeding $400 \mathrm{~mm} \mathrm{yr}^{-1}$ in Strategy 2. In Fig. 5 the resilience (Gunderson 2000) of the 2 strategies to annual rainfall changes can be compared. In the next scenario, we tested the resilience of this strategy to scenarios where annual temperatures may increase.

\subsection{Group 2 scenarios: sensitivity to temperature}

The sensitivity of Strategies 1 and 2 to rises in temperature is assessed in Fig. 6. The average annual temperature is raised in $1^{\circ} \mathrm{C}$ increments, from the average $22^{\circ} \mathrm{C}$ (no increase in annual temperature) to $27^{\circ} \mathrm{C}$ in each consecutive row of panels in Fig. 6, where total biofuel production in response to rainfall at each temperature is shown. In the model, total biofuel production in summed from total biodiesel and bioethanol production. Meeting a total biofuel production of approximately 400 million $1 \mathrm{yr}^{-1}$ would require a constant increase in annual rainfall, and the point at which rainfall meets the requirements of the Agricultural Land-use Strategy changes from the top to the bottom row of panels (see Fig. 6). This shows how climaterelated limits to growth can be assessed and verified, using Bayesian networks. These limits are not precise and predictive measurements of the system, but are intended to guide overall understanding of the system's critical limits and thresholds in a variety of scenarios. Other land-use strategies can also be assessed in different climate change scenarios in the manner outlined in this study.

\section{DISCUSSION}

Both the long- and short-term implications of human-development trajectories into the future are critical to understand if sustainable development trajectories are to be realised (Kates \& Clarke 1996). The Bayesian modelling framework is flexible and adaptable, and can support analyses of a wide range of future climate change and human development scenarios. The approach helps envisage cross-sector interdependencies, and to compare between system level trade-offs in an integrated analytical framework. It is also a flexible approach that allows for new evidence to be added and can serve as an input to learning (Demirez et al. 2006). Bayesian belief networks are as certain as the information used to characterise them, and reflect real-world uncertainties over cross-system and multi-scale interdependencies.

We showed how the national biofuel strategy of South Africa (and other countries) may be tested at the national scale before the identification and more indepth investigation of key subsystem dependencies. The model allows the assessment of various strategies against one another, which may be used to facilitate more focussed discussion around system interdependencies and cross-sector linkages at policy making and implementation level. The model is interdisciplinary and allows for a broad variety of variables to be linked, irrespective of scale or whether the variables are formulated using empirical data or subjective judgement. The sensitivities and uncertainties associated with all variables may be visualised and used to enhance decision-making processes through a broader consideration of system linkages. 

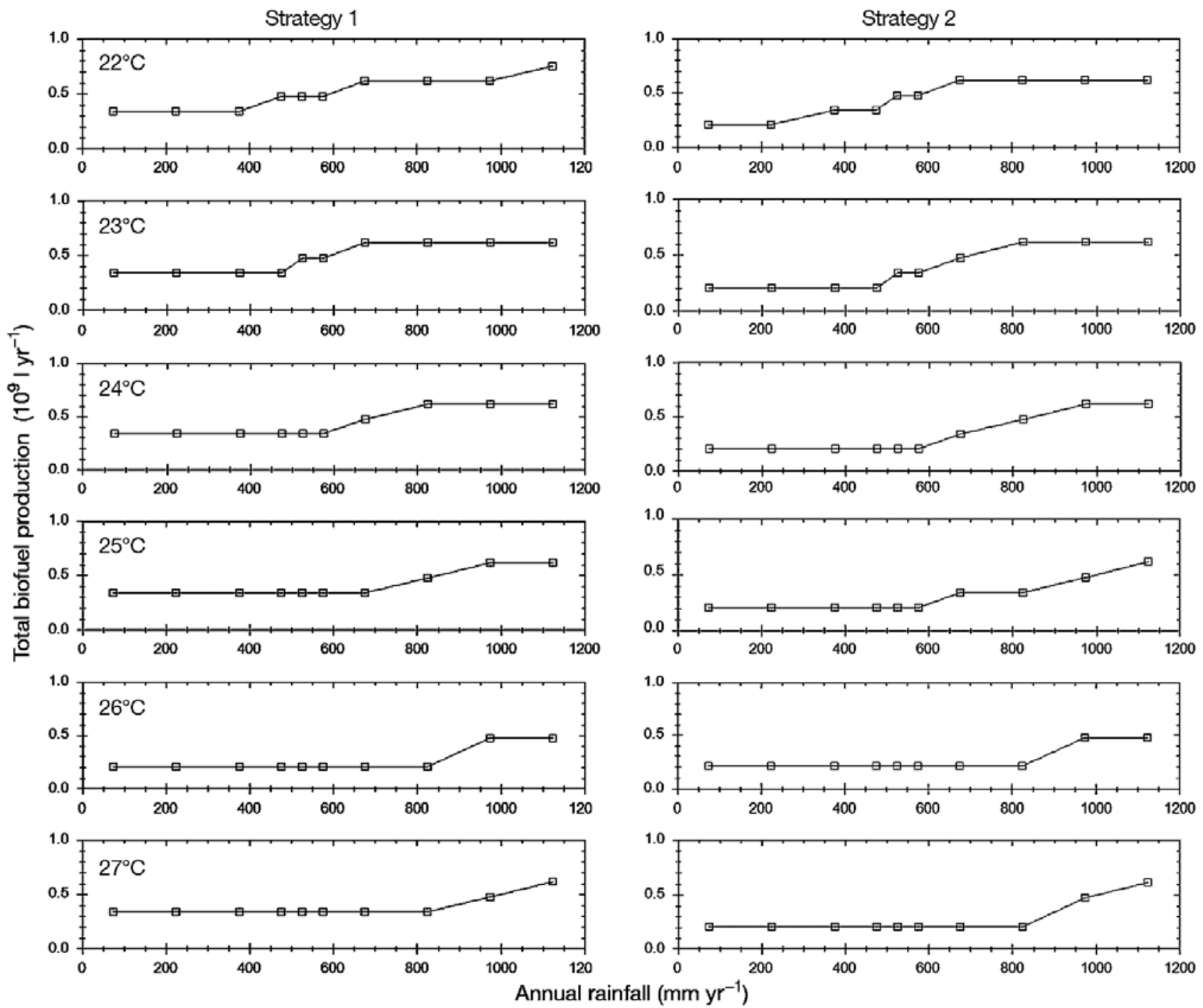

Fig. 6. Scenario 2a: increasing average annual temperature by $5^{\circ} \mathrm{C}$, in $1{ }^{\circ} \mathrm{C}$ increments by row of panels, to assess sensitivity to climate change conditions for land-use Strategies 1 and 2

In particular, this study shows how the energy-emissions threat to food security (the threat of rising energy needs and the need for lower emissions to food security through rising demand for biofuel crop production) can be considered using a Bayesian approach. If rising demands for energy and low emissions cause food prices to rise (as agricultural farming for biofuels becomes more lucrative and farmers dedicate larger tracts of land to crop strains suited for fuel production), then this approach can be used to identify the strengths and limitations of a particular land-use strategy.

\section{CONCLUSIONS}

This study showed how the national biofuels target may be analysed for robustness to climate change effects, using 2 particular biofuels production strategies as examples to illustrate how a variety of land-use agro-production combinations may be tested against a possible set of future scenarios and compared. The model presented in this study is multi-scale and consists of various embedded sub-system modules which are related through cross-sector interactions. The Bayesian software interface enables the model to be easily adapted with changes in understanding of sub-system inter-dependencies and sensitivities and may be used to facilitate and enable interdisciplinary consideration and scrutiny of adaptation responses under a variety of proposed scenarios. In this way, the approach taken in this study integrates top-down and bottom-up learning in a traceable process. Key parameters, thresholds and functional relationships defining the system are encoded into a Bayesian network using a software 
enabled knowledge engineering language to manage model development. Best available information from current literature and available data is used to constrain the probabilities in the Bayesian model, which is then verified through sensitivity analysis. The approach elucidates key sensitivities in the system, which depends on the scenario under which the system is being assessed. Sensitivity to scale and the exact nature of the causal interdependencies in the system may be iteratively probed and compared with observation and empirical data. Using this approach, understanding may be shared and iteratively improved in the consideration of policy-making for biofuels development programmes which have consequences in other related sectors.

\section{LITERATURE CITED}

Agarwal C, Green GL, Grove M, Evans T, Schweik C (2000) A review and assessment of land-use change models: dynamics of space, time and human choice. Centre for the Study of Institutions, Population and Environmental Change, Indiana University, Bloomington, IN

AQUASTAT (2005) FAO information system on water and agriculture. www.fao.org/ag/agl/aglw/aquastat/countries/ south_africa/print1.stm (accessed 10 July 2009)

Baran E, Jantunen T (2004) Stakeholder consultation for Bayesian decision support systems in environmental management. Proc Regional Conference on Ecological and Environmental Modeling, Universiti Sains Malaysia, 15-16 September, 2004

Bates BC, Kundzewics ZW, Wu S, Palutikof JP (eds) (2008) Climate change and water. Technical Paper of the Intergovernmental Panel on Climate Change. IPCC Secretariat, Geneva

Blignaut J, de Wit MP (2004) Sustainable options: development lessons from applied environmental economics. University of Cape Town Press, Cape Town

Borsuk ME, Stow CA, Reckhow KH (2004) A Bayesian network of eutrophication models for synthesis, prediction and uncertainty analysis. Ecol Model 173:219-239

Bromley J, Jackson NA, Clymer OJ, Giacomello AM, Jensen FV (2005) The use of Hugin to develop Bayesian networks as an aid to integrated water resource planning. Environ Model Softw 20:231-242

Demirez R, Mau RR, Shenoy C (2006) Bayesian networks: a decision tool to improve portfolio risk analysis. JAF 106119

DME (Department of Minerals and Energy) (2006) Draft biofuels industrial strategy of the Republic of South Africa. Department of Minerals and Energy. www.competebioafrica.net/policy/Biofuels_Strategy_SA.pdf

DME (2007) Biofuels industrial strategy of the Republic of South Africa.

Gunderson LH (2000) Ecological resilience-in theory and application. Annu Rev Ecol Syst 31:425-39

Gunderson LH, Holling CS (2002) (eds) Panarchy: under- standing transformations in human and natural systems. Island Press, Washington, DC

Hassan RM (2003) Economy-wide benefits from water intensive industries in South Africa: quasi-input-output analysis of the contribution of irrigation agriculture and cultivated plantations in the Crocodile River catchment. Development Southern Africa 20:171-195

Kates RW, Clarke WC (1996) Expecting the unexpected. Environment 38:6-11

Kates RW, Dasgupta P (2007) African poverty: a grand challenge for sustainability science. Proc Natl Acad Sci USA 104:16747-16750

Lemmer W (2006) Bio-ethanol production in the Western Cape: value adding to winter cereal through ethanol, DDGS, and $\mathrm{CO}_{2}$ production. Department of Agriculture, Cape Town

Levin SA (2006) Learning to live in a global commons: socioeconomic challenges for a sustainable environment. Ecol Res 21:328-333

> Lubchenco J (1998) Entering the century of the environment: a new social contract for science. Science 279:491-497

Malhotra Y (1999) Toward a knowledge ecology for organisational white-waters. Knowledge Manag 2:18-21

Meder B, Hagmayer Y, Waldmann MR (2009) The role of learning data in causal reasoning about observations and interventions. Mem Cognit 37:249-264

Mendelsohn R, Dinar A, Dalfelt A (2000) Climate change impacts on African agriculture. Centre for Environmental Economics and Policy in Africa, University of Pretoria

Midgeley GF, Chapman RA, Hewitson B, Johnston P and others (2005) A status quo, vulnerability and adaptation assessment of the physical and socio-economic effects of climate change in the Western Cape. Report to the Western Cape Government. Council for Scientific and Industrial Research Report No. ENV-S-C 2005-073, Stellenbosch

MIT Technology Review (2007) Ethanol demand threatens food prices. www.technologyreview.com/Energy/18173/ (accessed Feb 13, 2009)

Mukheibir P, Sparks D (2003) Water resource management and climate change in South Africa: visions, driving factors and sustainable development indicators. Report for Phase I of the Sustainable Development and Climate Change project. Energy and Development Research Centre (EDRC), University of Cape Town

Musango JM, Peter C (2007) A Bayesian approach towards facilitating climate change adaptation research on the South African agricultural sector. AGREKON 46:245-259

Peter C (2008) Complexity based modelling for sustainability and resilience of social-ecological systems. In: Burns M, Weaver A (eds) Exploring sustainability science-a southern African perspective. Stellenbosch University Press, Stellenbosch, p 471-505

Sugrue A, Douthwaite R (2007) Biofuel production and the threat to South Africa's food security. Wahenga Brief 11: 1-8, www.sarpn.org.za/documents/d0002509/Biofuel_SA_ Wahenga_Apr2007.pdf (accessed 15 July 2008)

Starzomski BM, Cardinale BJ, Dunne JA, Hillery MJ and others (2004) Contemporary visions of progress in ecology and thoughts for the future. Ecol Soc 9(1):14, www. ecologyandsociety.org/vol9/iss1/art14 (accessed 15 November 2007) 